\title{
EL MAESTRO DEL TÍMPANO DEL AMPARO DEL CLAUSTRO DE LA CATEDRAL DE PAMPLONA
}

\author{
Clara Fernández-Ladreda Aguadé \\ Universidad de Navarra
}

\begin{abstract}
RESUMEN: Entre los escultores que intervinieron en el claustro de la catedral de Pamplona destaca el maestro del tímpano del Amparo, obra que tradicionalmente ha Ilamado la atención por su originalidad iconográfica y formal. Se estudia la iconografía del tímpano y se plantea su posible inspiración en la pintura italiana de principios del XIV. Se examina su estilo y, en base a un análisis comparativo, se atribuyen al maestro una serie esculturas, localizadas en el claustro y otros lugares de Navarra. Además, a partir de la relación entre las obras claustrales y las fases constructivas del claustro, se plantea una cronología del artista, más temprana de la aceptada hasta ahora, en torno a 1310-1320. Finalmente, se aborda el problema de la filiación, rechazando la identificación con el maestro de Rieux, aunque admitiendo la existencia de vínculos con él, que llevan a pensar en una fuente común, localizada quizás en el sur de Francia, por el momento no identificada.
\end{abstract}

Palabras clave: Gótico, escultura, claustro catedral de Pamplona, Puente la Reina, Viana.

\section{THE MASTER OF THE AMPARO'S TYMPANUM OF THE PAMPLONA CATHEDRAL'S CLOISTER}

\begin{abstract}
Among the sculptors that developed their work at Pamplona cathedral's cloister, the master of the Amparo's tympanum highlights over others, due to its iconography and stilistic originality. The tympanum iconography is studied and its inspiration in 14th century's italian painting is proposed. His style is analysed and with comparison studies, other sculptures in the same cloister and other places in Navarra can be referred to him. Besides, from the relationship between the sculptures in the cloister and its constructive phases, an earlier chronology for this artist could be proposed, around 1310-1320. Finally, the problem of his artistic filiation is analysed, rejecting his identification with
\end{abstract}


Rieux's master, although knowing some links with him, fact that could mean a common origin in the south of France, not identified yet.

Keywords: Gothic, sculpture, cloister catedral of Pamplona, Puente la Reina, Viana.

El claustro de la catedral de Pamplona, levantado entre c. 1280 y 1330, fue, pese a sus dimensiones relativamente reducidas, un foco artístico relevante en su época, no solo en el contexto navarro sino hispano y aún europeo. En su realización participaron escultores que figuran entre los más destacados del momento: los autores de los capiteles y claves de las galerías oriental, septentrional y mitad norte de la occidental, el maestro del tímpano del Amparo, Guillermo Inglés y el maestro de la puerta Preciosa.

Aquí vamos a ocuparnos del maestro del tímpano del Amparo, cuya denominación procede de la considerada su obra cumbre, el tímpano de la puerta del Amparo, que comunica el claustro con el templo. A este artista y a su taller hay que atribuirles además las estatuas de san Pedro y san Pablo de la puerta de la capilla Barbazana y la ménsula de esta última ${ }^{1}$, y las claves de los vientos Subsolanus, Aquilón y Circius, y del río Fisón ${ }^{2}$. Fuera del ámbito catedralicio podemos adjudicarle las esculturas de Santiago y san Bartolomé de la parroquial de Santiago de Puente la Reina ${ }^{3}$ y las cabezas de la Dolorosa y san Juan procedentes de Viana, hoy en el Museo de Navarra ${ }^{4}$.

\section{Iconografía}

Su obras más relevante, el tímpano del Amparo $^{5}$ (Fig. 1) figura la muerte -Transitus o Dormitio- de la Virgen y la subida de su alma al cielo -Asumptio

1. URANGA GALDIANO, J. E. e ÍÑIGUEZ ALMECH, F., Arte medieval navarro. Pamplona, 1973, vol. V, p. 21, le atribuyeron las estatuas y sus respectivas ménsulas, pero, en nuestra opinión, la consola de san Pedro corresponde a otro maestro, el del Refectorio.

2. FERNÁNDEZ-LADREDA, C., "El maestro del tímpano del Amparo de la catedral de Pamplona. Nuevas obras", Pulchrum. Scripta varia in honorem $M^{a}$ Concepción García Gainza. Pamplona, 2011, pp. 312-314.

3. FERNÁNDEZ-LADREDA, C., "Análisis histórico-artístico", Fernández-Ladreda, C. y Roldan Marrodán, F. J., La puerta del Amparo de la catedral de Pamplona. Análisis histórico-artístico e informe de intervención. Pamplona, 2001, p. 17.

4. FERNÁNDEZZLADREDA, C. "El maestro...", p. 315.

5. Sobre la iconografía de este tímpano AZCÁRATE LUXÁN, M., "El Tránsito de la Virgen a través del Arte". Cuadernos de Arte e IConografía, t. 1, no 1 (1988), pp. 126-127; SILVA Y VERASTEGUI, M. a S. de, Iconografía Gótica en Álava. Vitoria, 1987, pp. 135-136 y 153; LAHOZ GUTIÉRREZ, L, "La Dormición de María en el arte gótico alavés". Boletín del Museo e Instituto Camón Aznar, XLIV (1991), p. 112; MARTíNEZ ÁLAVA, C., "La catedral gótica. Escultura", La catedral de Pamplona. Pamplona, 1994, t. I, pp. 307-310, y FERNÁNDEZ-LADREDA, 


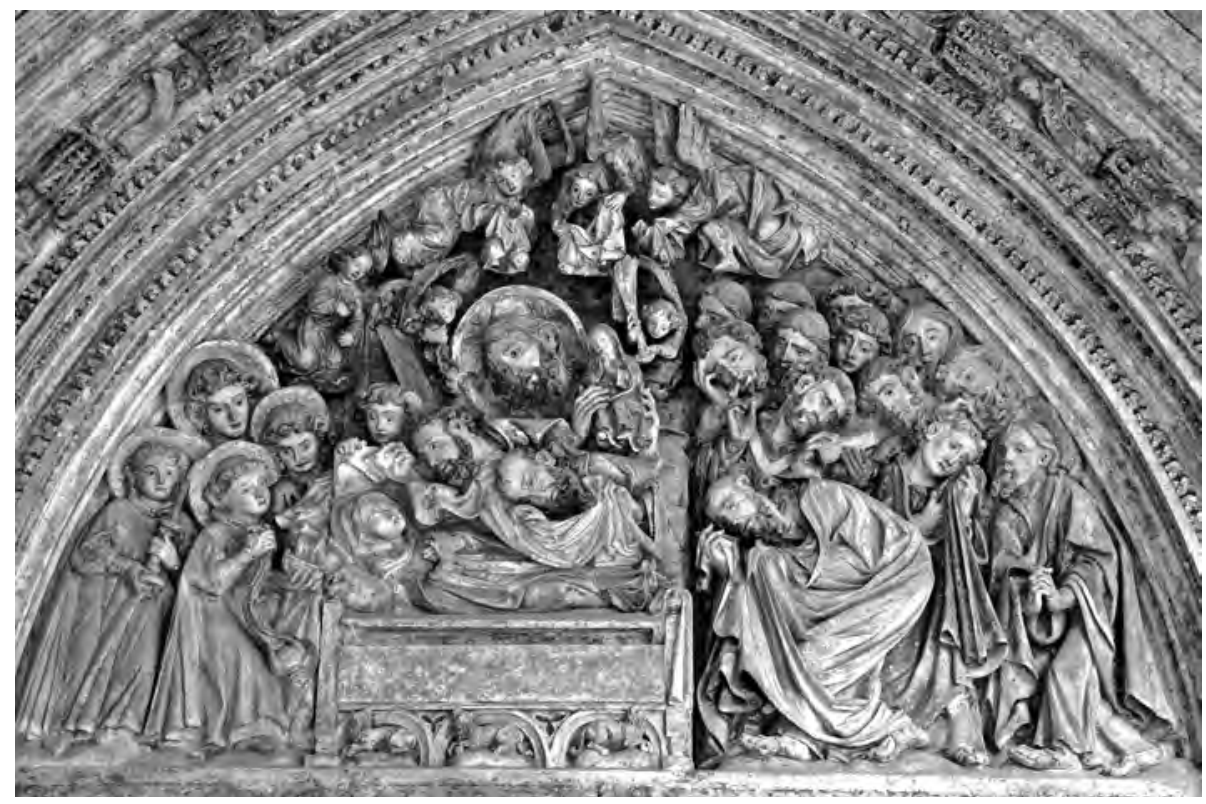

Figura 1. Tímpano de la puerta del Amparo. Claustro de la catedral de Pamplona.

animae-. En la parte central, en la zona inferior, el cuerpo de María, colocado sobre un sarcófago, está siendo cubierto con el sudario por san Pedro y san Pablo -reconocible por su característica calvicie frontal solo interrumpida por la presencia de un mechón en el centro- ayudados por un ángel; sobre ellos, en la zona media, aparece Cristo -perfectamente identificable por su gran nimbo- llevando en brazos una pequeña figura en actitud orante -el alma de la Virgen-, flanqueado por sendos ángeles, uno de los cuales agita un incensario y el otro porta la palma; finalmente, en la parte superior, otros tres ángeles con paños en las manos se disponen a ayudar a Cristo. A la derecha los apóstoles, incluidos de nuevo san Pedro y san $\mathrm{Pablo}^{6}$, asisten llorosos a la liturgia funeraria; puede reconocerse a san Pedro, por su condición de director de la ceremonia -lee y bendice-, a san Pablo -que ocupa una posición destacada, justo

C., "Análisis...", pp. 8-11. Más recientemente HIDALGO SÁNCHEZ, S., "Función, composición, modelo y tema: el tímpano de la Dormición en el claustro de Pamplona". Anales de Historia del Arte, 2010 vol. extraordinario, pp. 247-257, centrado en el aspecto funcional y su influjo en la elección del tema.

6. La inclusión de san Pablo explica que los apóstoles sean trece y no doce. Como, por otra parte, san Pedro y san Pablo habían aparecido antes amortajando a la Virgen, esto explica que el tímpano ofrezca un total de quince apóstoles, lo que resulta a primera vista y hasta que se comprende lo que ocurre algo chocante. 
a los pies del sepulcro mariano-, por ser un doble perfecto del anterior, y a san Juan -que está inmediatamente detrás-, por ser el único imberbe. En el lado opuesto a los apóstoles encontramos cuatro jóvenes nimbados ${ }^{7}$ : dos de ellos actúan como acólitos en la celebración litúrgica, portando uno un incensario y una naveta y el otro un cirio, y el tercero ayuda a amortajar a María. La temática del tímpano continúa en la única arquivolta figurada -que, aunque obra de otro taller ${ }^{8}$, iconográficamente forma parte del mismo conjunto que el tímpano-, en la que aparecen doce personajes -seis a cada lado- representando a los santos de todo genero que constituían la escolta de Cristo, distribuidos por parejas: de arriba abajo tenemos ángeles, vírgenes -una de las cuales quizás sea santa Catalina-, confesores -representados por obispos tocados con mitra-, mártires cefalóforos -uno de ellos san Dionisio y el otro muy probablemente san Nicasio-, profetas y diáconos. Todos ellos portan filacterias con palabras pintadas -actualmente casi borradas-, que componían la inscripción Quae est ista quae ascendit de deserto deliciis affluens, innixa super dilectum suum? Asumpta est Maria in coelum ${ }^{9}$.

En última instancia su fuente textual parece ser la Leyenda Aurea de Santiago de Vorágine, pues prácticamente todo lo descrito se cita allí10: la presencia en el tránsito de María de la totalidad de los apóstoles incluido san Pablo, la salida del alma de la Virgen de su cuerpo y su subida al cielo en los brazos de Cristo, el séquito compuesto por ángeles, profetas, mártires, confesores y vírgenes entonan-

7. VÁZQUEZ DE PARGA, L., "La Dormición de la Virgen en la catedral de Pamplona". Príncipe de Viana, VII (1946), p. 257 y SILVA Y VERASTEGUI, M. ․ S. de, Iconografía..., pp. 136 y 153 , los identificaron como ángeles, pese a la carencia de alas. No les falta razón, ya que efectivamente están basados en los ángeles que actúan como acólitos en representaciones de la Dormición italianas -vid. nota 20-, lo que ocurre es que, probablemente por falta de espacio, se les han suprimido las alas.

8. El de Guillermo Inglés.

9. El texto actualmente está casi perdido, pero fue recogido por ALVARADO, F. de, Guía del viajero en Pamplona. Madrid, 1904, p. 37. De todos modos se conservan aún algunas palabras que permiten confirmar la exactitud de la transcripción.

10. VORÁGINE, S. de la, La Leyenda Dorada. Madrid, 1996, vol. I, pp. 477-498, especialmente 478-481 y 490-491. Ciertamente más o menos los mismos episodios figuran en otros apócrifos, pero hay que recordar que la propia Leyenda incorpora apócrifos anteriores. Los únicos elementos que no figuran en la Leyenda ni en los apócrifos son los cuatro jóvenes nimbados de la izquierda del tímpano, sobre cuyo origen hablaremos más adelante.

El conocimiento de apócrifos asuncionistas en la iglesia pamplonesa en la época de la realización de la puerta del Amparo queda demostrado por la frase recogida en la liturgia establecida por el obispo Barbazan en el Sínodo de 1354 -y mencionada en breviarios coetáneospara la vigilia de la Asunción, que debía ser guardada por todo el clero de la diócesis, cabildo catedralicio incluido: Ne forte si venerit vestris in manibus illud apocriphum de transitu eiusdem virginis... -ARIGITA, M., La Asunción de la Santísima Virgen y su culto en Navarra. Madrid, 1910, pp. 45 y 50- 
do cánticos -incluso la primera frase de los mismos ${ }^{11}-$, la actuación de san Pedro como director de la liturgia y la presencia de la palma llevada por un ángel ${ }^{12}$.

Con todo es muy probable que -como ocurre a menudo- la fuente de inspiración haya sido otra obra de arte. En esta línea se han planteado dos hipótesis. Según una, el tímpano del Amparo empleaba la fórmula bizantina de la Koimesis -Dormición-, transmitida a través de las portadas francesas del último tercio del XII y del XIII dedicadas al ciclo de la muerte, asunción y coronación de la Virgen, como Mantes, Chartres o Estrasburgo, y suponía la persistencia de una tradición ${ }^{13}$. Según otra, el esquema iconográfico empleado es el bizantino, pero está tomado de modelos italianos, influidos a su vez por Bizancio, y desde esta perspectiva no resulta tradicional sino novedoso, pues los italianos no lo generalizaron hasta fines del XIII y principios del XIV ${ }^{14}$.

Ahora bien, si cotejamos el tímpano pamplonés con las citadas portadas francesas encontramos Ilamativas diferencias. Algunas fueron advertidas con anterioridad, como la figuración de una sola escena y además de la Dormición en concreto $^{15}$, pues en las portadas galas ese episodio no aparece aislado sino que se halla asociado a otras escenas del ciclo de la muerte de la Virgen ${ }^{16}$ y particularmente a la Coronación, y de representar una sola escena se da preferencia precisamente a ésta ${ }^{17}$. Otras no habían sido señaladas, como los ángeles

11. Que a su vez está basada en el Cantar de los Cantares (Cant. 3,6). Ciertamente la Leyenda Dorada no atribuye esta estrofa a los santos que componían el séquito que acompañaba a Cristo sino a los que habían quedado en el cielo, pero su transposición a aquellos resulta bastante explicable.

12. La palma aparece en un contexto distinto del citado por la Leyenda Dorada, pues allí era entregada a la Virgen por el ángel que le anunciaba su muerte y era llevada en el cortejo funerario por san Juan, desempeñando un papel clave en la milagrosa curación de los judíos, mientras que en el tímpano aparece en manos de uno de los ángeles que escoltan a Cristo.

13. SILVA Y VERASTEGUI, M. ․ S. de, IConografía..., p. 153. Lo dice con relación a la portada de Laguardia, pero es claro, por el contexto, que se puede aplicar a la del Amparo, a la que se refiere inmediatamente a continuación.

14. LAHOZ GUTIÉRREZ, L., "La Dormición...", p. 115 y LAHOZ GUTIÉRREZ, L., "Sobre la ascendencia navarra en la plástica gótica del País Vasco". Tercer Congreso General de Historia de Navarra, Área II. Corrientes artísticas, Ponencia I. El Arte gótico en Navarra en el panorama europeo. Reflexiones sobre la recepción y asimilación de fórmulas novedosas, Pamplona, 2023 septiembre de 1994, pp. 7-9.

15. La primera por FERNÁNDEZ-LADREDA, C., "Análisis...", p. 11. La segunda por HIDALGO SÁNCHEZ, S., "Función...", p. 250.

16. Se suele citar, erróneamente, como precedente y paralelo en la representación aislada de la Dormición el tímpano del crucero sur de Estrasburgo, pero en Estrasburgo el tímpano con el tema de la Dormición se completa con la representación de los funerales -en el dintel-y con la Coronación y Asunción corporal -en el otro portal, pues se trata de un portal doble-.

17. Tal es el caso del portal occidental central de Reims donde solo aparece la Coronación, aunque no exactamente en el tímpano sino en el gablete -si bien hay que tener en cuenta que el dintel original fue destruido en la Revolución, por lo que quizás la situación primitiva fuera distinta-, de la puerta roja de Nôtre Dame de París y del tímpano de Moûtiers-Saint-Jean. 
voladores llevando paños y otros objetos -incensario, palma- que escoltan a Cristo, san Pedro como director de la liturgia leyendo un libro, los jóvenes acólitos portando cirios e incensarios y ayudando a amortajar a María, y el séquito de ángeles y santos de la arquivolta, presentes en la portada pamplonesa y ausentes en las francesas ${ }^{18}$.

Por el contrario, estos elementos, tomados a su vez de obras bizantinas ${ }^{19}$, figuran en representaciones pictóricas italianas, entre las que destaca la tabla de Giotto del Gemäldegalerie de Berlín (datada entre 1311 y 1315) ${ }^{20}$, que resulta con mucho la más similar a nuestro tímpano, hasta tal punto que parece probable que nuestro escultor se inspirara en ella o en alguna obra similar, hoy perdida. Por lo tanto, aunque la idea del empleo del tema de la Dormición en una portada pueda estar inspirada en Francia ${ }^{21}$, parece que hay que concluir con

18. La única excepción -y parcial- sería Chartes que incluye en la arquivolta interior ángeles turiferarios o con otros atributos, pero incluso en Chartres faltan los ángeles del tímpano y los santos de la arquivolta.

19. DUHR, J., "La Dormition de Marie dans I'art chrétien". Nouvelle revue théologique, LXXII, 1 (1950), p. 146, y VERDIER, P., Le Couronnement de la Vièrge: les origins et les premiers développements d'un thème iconographique. Montreal, 1980, p. 59.

20. Los ángeles con paños en las manos escoltando a Cristo los encontramos en los mosaicos de Santa María la Mayor de Jacobo Torriti (encargado por Nicolás IV, o sea entre 1288 y 1292, y terminado tras su muerte, en 1295) y de Santa María in Transtevere de Pietro Cavallini (realizado en 1291 ó 1298) -VERDIER, P., Le Couronnement..., pp. 158-161-. A san Pedro como director de la liturgia lo vemos de nuevo en los citados mosaicos de Santa María la Mayor y Santa María in Transtevere, si bien allí porta un incensario, y en la tabla de la Gemäldegalerie de Berlín de Giotto (datada entre 1311 y 1315) -BOSKOVITS, M., "Giotto: un artista poco conosciuto?", TARTUFERI, A., Giotto. Bilancio critico di sessanti anni di studi e ricerche. Florencia, 2000, p. 86-, en la que ya aparece leyendo. Por su parte los jóvenes acólitos portando uno un cirio, otro un incensario y el tercero ayudando a amortajar a María podrían estar inspirados en la misma obra de Giotto o en una similar; efectivamente en la citada tabla aparecen varios ángeles como acólitos portando cirios e incensario, mientras otro ángel ubicado a la cabecera coge el sudario para amortajar a María; ahora bien, no solo sus acciones coinciden con las de los acólitos de Pamplona, sino que incluso están nimbados como ellos y además en el caso de los cuatro primeros su apariencia juvenil y la larga túnica sin manto que visten concuerdan con el aspecto e indumentaria de los acólitos del tímpano. El séquito de ángeles y santos lo encontramos en un fresco de la basílica superior de Asís obra de Cimabue (fechado entre 1278-1280) -VERDIER, P., Le Couronnement..., p. 154, y LUNGHI, E., The Basilica of St. Francis at Assisi. Florencia, 1996, pp. 28, 31-32-, en el retablo de la Maestá de la catedral de Siena de Duccio (1308-1311) y de nuevo en la tabla de Giotto.

21. Efectivamente en Italia, no he localizado portadas con una iconografía similar a la de la puerta del Amparo. Cabría pensar en la desaparecida puerta sur de la catedral de Florencia de Arnolfo di Cambio, datada c. 1300, de la que se conservan restos, un dibujo y una descripción. Sin embargo, conviene recordar, por una parte, su excepcionalidad en el contexto italiano y, por otra, sus conexiones con el gótico nórdico, en concreto con el tímpano de Estrasburgo -WILLIAMSON, P., Gothic sculpture, 1140-1300. New Haven, 1995, pp. 258-259-. Ahora bien, sí la hipótesis de la similitud con Estrasburgo es correcta y sí solo contaba con las figuras mencionadas en la descripción, debía ser muy similar a las portadas francesas -no solo Estras- 
Lahoz que el modelo iconográfico adoptado está tomado de Italia, que lo recibió de Bizancio, y que desde esta perspectiva no resulta tradicional sino novedoso. En realidad, esta influencia italiana no resulta insólita, pues la encontramos en otras obras catedralicias tanto escultóricas como pictóricas ${ }^{22}$.

La elección de la Dormición con su correspondiente asunción del alma se explica, creemos, en función de la advocación de la catedral pamplonesa, que estaba dedicada a la Virgen en el misterio de su Asunción ${ }^{23}$, pues además la asunción del alma no solo representaba ésta sino que -al igual que en Cataluña- tenía probablemente un significado polivalente y aludía también en último término a la asunción corporal, creencia aceptada como doctrina cierta por la mayoría de la Iglesia y desde luego por la iglesia navarra y el obispo Barbazan, como demuestra la liturgia establecida por este prelado para la vigilia de la Asunción en el Sínodo de 1354 -y mencionada en breviarios coetáneos-, que debía ser guardada por todo el clero de la diócesis ${ }^{24}$. En esta línea conviene tener en cuenta que la puerta del Amparo fue, por añadidura, la primera portada catedralicia en la que hubo la posibilidad de presentar una iconografía asuncionista, en armonía con la dedicación del templo, y parece lógico que no se desaprovechara ${ }^{25}$.

Recientemente, se ha apuntado otra razón para la elección del tema de la Dormición -es decir la muerte de la Virgen-, poniendo de relieve que resultaba particularmente acorde con la función funeraria del claustro, ya que además durante la Edad Media la muerte de María fue el prototipo de la buena muerte $^{26}$. En este sentido podemos argüir además que la relación entre la temática de las portadas claustrales y la función del claustro o la de las depen-

burgo, sino también Mantes o Chartres-y, por consiguiente, como ellas, bastante diferente de la del Amparo.

22. Para la escultura FERNÁNDEZ-LADREDA, C., "El gótico navarro en el contexto hispánico y europeo", Cuadernos de la Cátedra de Patrimonio y Arte Navarro, no 3. Presencia e influencias exteriores en el arte navarro, Actas del Congreso Nacional. Pamplona, 5-7 de noviembre de 2008. Pamplona, 2008, pp. 98 y 99-100. Para la pintura LACARRA DUCAY, M. ${ }^{a}$ C., Aportación al estudio de la pintura mural gótica en Navarra. Pamplona, 1974, pp. 299-336, y LACARRA DUCAY, M. ${ }^{\mathrm{a}}$ C., "Los murales de la catedral de Pamplona. Influencia de la escuela de Siena en la pintura navarra del siglo XIV". Reales Sitios, XXI, no 82 (1984), pp. 65-72.

23. FERNÁNDEZ-LADREDA, C., "Análisis...", p. 11.

24. HIDALGO SÁNCHEZ, S., Recherches sur la sculpture du cloître gothique de Pampelune, ses commanditaires et ses relations avec le midi de la France. Memoire de DEA (inédita), CESCM de la Université de Poitiers, 2005, pp. 61-63.

25. Cuando se levantó esta portada, el templo catedralicio no era el actual gótico sino su antecesor románico y sus portadas, aunque ignoramos su temática exacta -fueron destruidas en el XVIII y solo se conservan escasos restos-, dada su cronología -c. 1117-1118 y en todo caso anterior a 1127-, difícilmente podían incluir temas asuncionistas.

26. HIDALGO SÁNCHEZ, S., "Función...", pp. 253-255. 
dencias a las que daban acceso -capítulo, refectorio, dormitorio- constituye una constante ${ }^{27}$.

Parece probable que la iconografía de esta portada, no solo del tímpano y la arquivolta sino del conjunto, haya sido determinada por el obispo, Arnaldo de Barbazán (1318-1355), pues resulta muy acorde con las circunstancias de este prelado. Por un lado, sabemos que fue hombre culto y preocupado por la liturgia y el culto divino en general -como lo demuestran las decisiones en este sentido adoptadas en los diferentes sínodos diocesanos que convocó y el hecho de que durante su episcopado se confeccionaron dos breviarios para uso de la catedral de Pamplona y una regla para regular el canto del oficio divino en la misma- y que además prestó especial atención a la liturgia y devoción marianas, elevando la categoría litúrgica del oficio de la Virgen de los sábados e introduciendo en la diócesis el rezo del Ángelus ${ }^{28}$, y -lo que resulta especialmente relevante y significativo- que se interesó por la liturgia asuncionista en concreto, reglamentando los oficios desde la vigilia de la festividad de la Asunción hasta la culminación de su octava $^{29}$. Por otro, varios de los santos de las arquivoltas son franceses al igual que el prelado, como san Dionisio y san Nicasio, o gozaron de la predilección del obispo, como santa Catalina, patente en el hecho de que elevara la categoría litúrgica de su fiesta y estableciera una cofradía dedicada a ella ${ }^{30}$.

En las estatuas de san Pedro y san Pablo (Fig. 2), que adornan las jambas de la puerta de la capilla Barbazana, sus facciones se ajustan al "retrato tipo" de ambos apóstoles y se asemejan bastante a las de sus equivalentes de la puerta del Amparo, lo que bastaría para identificarlos, pero además portaban sus atributos característicos - llaves para san Pedro y espada para san Pablo, y libro para los dos $^{31}-$. De nuevo habría que relacionar la elección de estos personajes concretos con la función de esta dependencia, pues no hay que olvidar que fue concebida como sala capitular, y que la colocación de imágenes apostólicas en los claustros y más en concreto flanqueando la puerta de entrada al capítulo contaba con una larga tradición que arrancaba del románico ${ }^{32}$. A través de ellas

27. Sobre la relación entre la iconografía de la puerta del capítulo y la dependencia en cuestión infra. Para el resto HIDALGO SÁNCHEZ, S., "El ciclo de la Dormición en el claustro de la catedral de Pamplona". Revue Mabillon, 22 (2011), pp. 159-160.

28. GOÑI GAZTAMBIDE, J., Historia de los obispos de Pamplona. Pamplona, 1979, vol. II, pp. $144-152$ y 168.

29. ARIGITA, M., La Asunción..., pp. 45-61.

30. Que Barbazán era devoto de los santos franceses y aún de carácter muy local lo demuestra el que elevara la categoría litúrgica de las fiestas de san Antonio de Vienne y san Antonio mártir de Pamiers, de cuya diócesis por cierto había sido canónigo -GOÑI GAZTAMBIDE, J., Historia..., p. 152-. Sobre su devoción a santa Catalina GOÑI GAZTAMBIDE, J., Historia..., pp.147 y 168 .

31. Actualmente las llaves y la espada están casi perdidos.

32. Por ejemplo, la sala capitular de la catedral de León, construida hacia 1200, contaba también con estatuas de san Pedro y san Pablo, colocadas al parecer en la puerta de entrada, 
Figura 2. Estatuas de san Pedro y san Pablo de la puerta de la capilla Barbazana. Claustro de la catedral de Pamplona.
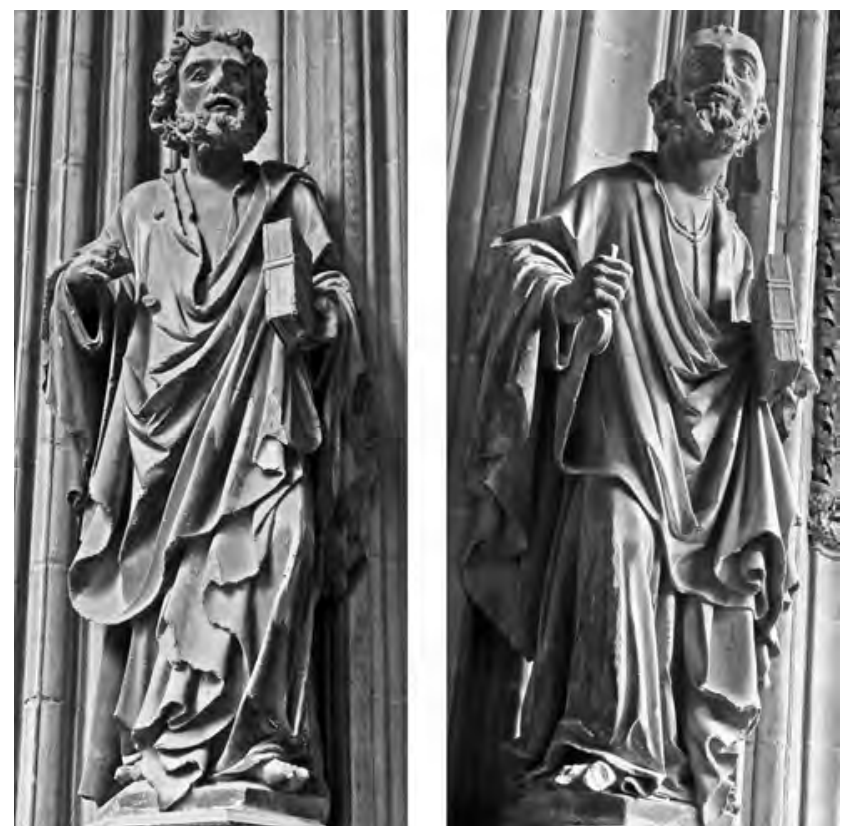

se recordaba que la vita apostólica era el modelo ideal de la vita communis y el cabildo pamplonés se caracterizó precisamente por su excepcional apego a esta fórmula, que le llevó a prolongarla hasta 1860.

Como es usual, las ménsulas que las sustentaban muestran escenas relacionadas con ambos personajes. La de san Pablo representa dos episodios de la vida del santo: la recepción de las cartas para las sinagogas de Damasco autorizándole para prender a los cristianos de manos del sumo sacerdote y la aparición de Cristo cuando iba camino de esa ciudad (Hechos 9, 1-8) 3 $^{33}$ La de san Pedro, en cambio, hace referencia a un pasaje de sus escritos -Sed sobrios y vigilad, que vuestro adversario el diablo, como león rugiente, anda rondando y busca a quien devorar, al cual resistiréis firmes en la fe (1P. 5, 8-9)-, alusivo a la constante lucha del cristiano como miles Christi con los poderes infernales ${ }^{34}$, a través de la representación de un caballero armado con escudo y espada que

en la cara interna de las jambas -SÁNCHEZ AMEIJEIRAS, R., "Una empresa olvidada del primer gótico hispano: la fachada de la sala capitular de la catedral de León". Archivo español de Arte, LXIX (1996), pp. 397-399 y 404-.

33. MARTíNEZ ÁLAVA, C., "La catedral...", p. 319.

34. Con anterioridad se dieron otras interpretaciones más discutibles, ésta fue expuesta por MARTíNEZ DE AGUIRRE, J. y MENÉNDEZ PIDAL, F., Emblemas heráldicos en el Arte Medieval Navarro. Pamplona, 1996, pp. 258-259. 

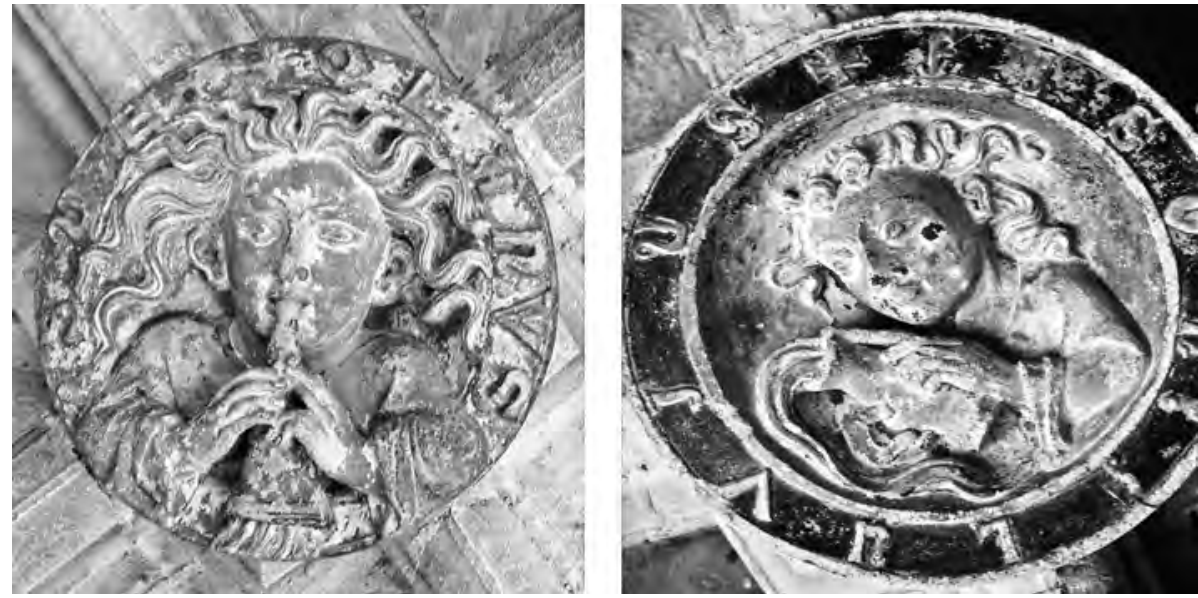

Figura 3. Claves del viento Subsolano y del río Fisón. Claustro de la catedral de Pamplona.

se enfrenta a un feroz león, mientras su caballo pisotea un dragón ${ }^{35}$. La presencia de este último lleva a pensar asimismo en un cierto influjo del Salmo XC, 13 -Pisarás sobre áspides y víboras, y hollarás el león y el dragón-, concretamente de su segunda parte, que hace referencia a un tema relacionado con el anterior, los efectos de la protección divina sobre el justo.

La iconografía de las claves (Fig. 3) de los vientos Subsolano, Aquilón y Circius $^{36}$ siguen la fórmula empleada desde la Antigüedad clásica: un hombre joven soplando una trompa. También la clave del río Fisón adopta el modelo clásico: un joven portando un jarro del que brota agua. En todas ellas la figura se reduce al busto, aunque incluye los brazos, y el personaje está identificado por una inscripción que recorre la orla de la clave.

En cuanto a las estatuas puentesinas, Santiago se encuentra caracterizado como peregrino, tocado con sombrero decorado con veneras, sujetando en la diestra el bordón y portando en la izquierda un libro (Fig. 4). San Bartolomé, por su parte, también sostiene en la mano izquierda un libro, mientras en la derecha probablemente Ilevaba el cuchillo instrumento de su martirio, e iba acom-

35. Aunque describimos aquí su iconografía, pues guarda relación con la escultura de san Pedro, que sustenta, con la que forma un conjunto, estilísticamente, como ya apuntamos -vid. nota 1-, es obra de otro maestro, el del Refectorio.

36. Sobre el programa iconográfico de las claves de temática profana del claustro de Pamplona, FERNÁNDEZ-LADREDA, C., "La decoración escultórica del claustro de la Catedral de Pamplona: capiteles y claves figurativos". Cuadernos de la Cátedra de Patrimonio y Arte Navarro, $\mathrm{n}^{\circ}$ 1, Estudios sobre la catedral de Pamplona: in memorian Jesús M. aㅡ Omeñaca. Pamplona, 2006, pp. 39-41. 
pañado por el diablo, actualmente desaparecido, pero cuya silueta se conserva. Del san Juan y la Dolorosa de Viana, dado que solo se conservan las cabezas, poco podemos decir.

\section{Estilo}

Desde el punto de vista formal, el tímpano del Amparo es sin duda la pieza más relevante, por la magnitud y calidad, y de ahí que nos sirva de pauta a la hora de establecer las características estilísticas del $\operatorname{artista~}^{37}$.

En primer lugar hay que destacar el criterio compositivo, definido por el abigarramiento y el recargamiento -cabe hablar de un auténtico horror vacui-, con numerosas figuras, de gran tamaño además, lo que se traduce en una cierta confusión, pero contribuye a incrementar el efecto dramático. Hay que reseñar asimismo el énfasis puesto en marcar la tercera dimensión, a través de la colocación de los personajes en distintos planos -Apóstoles de la derecha- y del empleo de un relieve muy profundo -figuras del primer plano cuyas cabezas están casi exentas-. Se trata de características que resultan insólitas en el contexto de la escultura monumental gótica anterior o coetánea, tanto hispana como francesa $-y$ de hecho ya tradicionalmente se ha destacado esta excepcionalidad-, pero que resultan lógicas y comprensibles sí su fuente de inspiración fueron pinturas italianas, pues en ellas, en particular en las obras de Cimabue, Duccio y Giotto citadas ${ }^{38}$, encontramos los mismos rasgos. La originalidad formal del tímpano del Amparo, que tanto

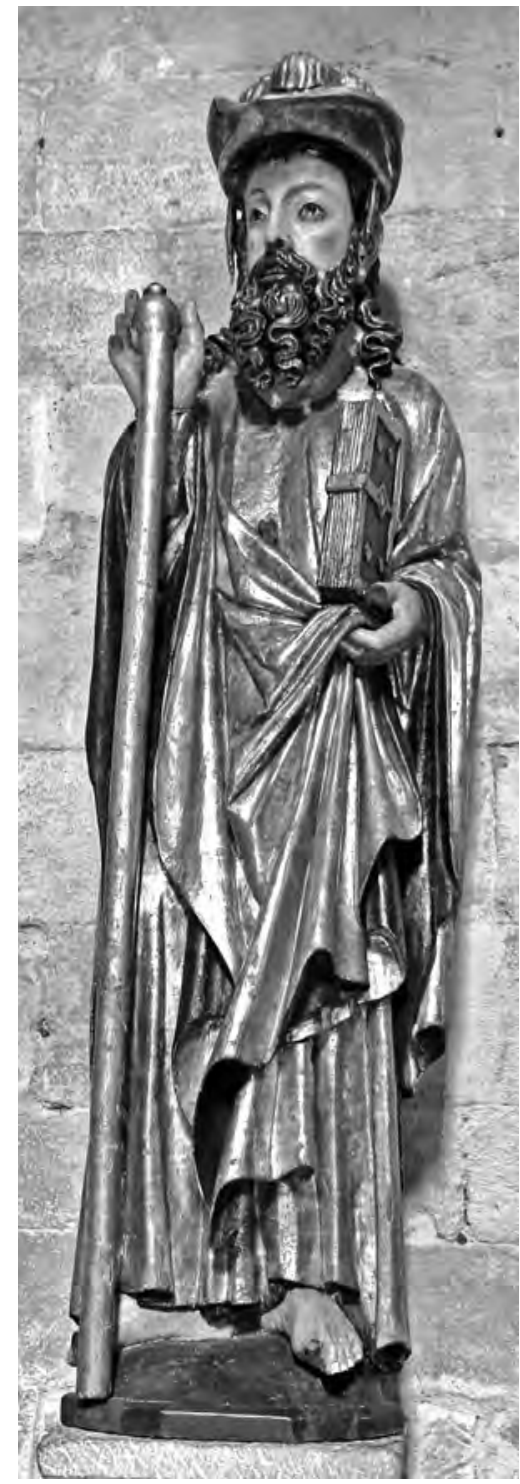

Figura 4. Estatua de Santiago. Iglesia de Santiago de Puente la Reina (foto cortesía Sagarte).

37. Sobre el estilo de este tímpano MARTíNEZ ÁLAVA, C., "La catedral...", pp. 311-313 y 316, y FERNÁNDEZ-LADREDA, C., "Análisis...", pp. 15-16.

38. Nota 20. 
ha llamado la atención y tantos quebraderos de cabeza ha causado a los historiadores del arte, se explica así porque nos hallamos ante la trasposición de unos rasgos más bien propios de un genero artístico -la pintura- a otro distinto -la escultura-.

Las figuras adoptan con frecuencia posturas forzadas y presentan algunas desproporciones -macrocefalia, manos y pies excesivamente grandes-. Las cabezas, en los varones adultos -Cristo y los Apóstoles- son más bien alargadas, con unos rasgos muy acusados y característicos: frentes arrugadas, entrecejos marcados y cejas fruncidos, orejas muy desarrolladas y detalladas, ojos grandes, hundidos, ligeramente rasgados, con los párpados superior e inferior perfectamente dibujados, pómulos acusados, líneas nasolabiales bien visibles, narices largas en ocasiones ligeramente aguileñas en las que se han tallado incluso las aletas y orificios nasales, y bocas grandes y a veces entreabiertas dejando ver los dientes. Este tratamiento de las facciones confiere expresividad a los rostros, reflejando el dolor que les embarga. Se ha hablado de realismo e individualización, pero conviene matizar, pues si bien en conjunto resultan realistas, se trata de un realismo genérico y no individualizado: en realidad, nos hallamos ante un arquetipo facial que se repite con ligeras variantes en todos los personajes y la individualización no viene dada por los rasgos sino por las barbas y cabellos. En lo que se refiere al peinado se distinguen básicamente dos variantes: la melena relativamente larga, partida por raya al medio con sendas ondas laterales muy pronunciadas a la altura de las orejas, o el pelo más bien corto, tonsurado o no, sin raya y con el borde surcado por marcados rizos en forma de meandros muy característicos; excepcionalmente en el caso de san Pablo se emplea una variante de este último, pero con la calvicie típica de este santo y el pelo mucho más largo aunque con idénticos rizos. Las barbas son básicamente iguales, a base de mechones ondulados, con un tratamiento similar al de los rizos del borde del cabello de la segunda modalidad; en todo caso, las de Cristo y san Pablo son algo más largas.

En el único rostro femenino -Virgen- y en los rostros masculinos juveniles -acólitos y ángeles- se trata por el contrario de dar una visión de belleza idealizada, intemporal y sobrenatural, de ahí el empleo de una tipología muy diferente, con rostros redondos, de rasgos suaves y delicados, mucho menos marcados: por supuesto han desaparecido las arrugas de la frente, se ha eliminado el entrecejo y las cejas fruncidas, y las líneas nasolabiales son mucho menos notorias. Incluso el tratamiento de los cabellos, que corresponde a la segunda variante, es prácticamente igual en todos, con lo que se ha suprimido la sensación de individualización.

En las telas Ilama la atención el tratamiento del plegado con preferencia por los pliegues angulosos muy marcados, voluminosos y plásticos, característica que se acentúa al ir enmarcados por zonas rehundidas -Apóstoles del primer plano, mortaja de la Virgen, ángeles con paños de la parte superior-. Esta configuración del plegado, unido al acusado modelado de los rasgos faciales y al 
empleo del relieve profundo, ya citados, se traduce en la aparición de fuertes contrastes de claroscuro que refuerzan el carácter dramático de la escena.

Las mismas características en cuanto a posturas, proporciones de los cuerpos y tratamiento del plegado encontramos en las estatuas de san Pedro y san Pablo de la puerta de la capilla Barbazana ${ }^{39}$. Las cabezas corresponden, lógicamente, al primer modelo, el de los varones adultos, y repiten los rasgos faciales y la tipología de cabellos y barbas vistos en ellos e, incluso, pretenden asimilarse al de sus equivalentes del tímpano, como ya apuntamos.

En el caso de las claves ${ }^{40}$, las caras del viento Subsolano y del río Fisón se adscriben en cambio al segundo modelo, el de los rostros masculinos juveniles. La de Subsolano resulta muy semejante a las del acólito y el ángel que ayudan a desplegar el sudario sobre el cuerpo de la Virgen, el acólito ceroferario y el ángel de la izquierda de la hilera superior. La larga y vistosa melena está compuesta por mechones ondulados dispuestos radialmente, que recuerdan a los que integran la cabellera del apóstol san Pablo lloroso. Por su parte el rostro de Fisón se parece mucho a los del acólito turiferario y el emplazado justo sobre él y el ángel del centro de la hilera superior. El tratamiento del cabello remite al acólito y el ángel que despliegan el sudario, el ángel turiferario que está a la derecha de Cristo y el situado sobre la cabeza de éste que porta un paño. La clave del viento Aquilón sigue el modelo de la de Subsolano, si bien acusa un descenso de calidad, que parece indicar que es obra de un discípulo. A su vez, la de Circius parece inspirada en la de Aquilón, pero de nuevo pierde calidad respecto al prototipo en tal grado que más que a un discípulo cabe adscribirla a un aprendiz.

En cuanto a las estatuas de Santiago y san Bartolomé de la parroquial de Santiago de Puente la Reina ${ }^{41}$ conviene advertir que la primera está ejecutada en madera, lo que constituye un caso único dentro de la producción conocida del maestro, algo explicable posiblemente porque, al tratarse del titular del templo, sin duda tenía función procesional. Este hecho justifica su postura, rígida y hierática, igualmente insólita dentro del repertorio del artista, impuesta por el formato del tronco en que fue labrada. En cambio san Bartolomé presenta una posición ligeramente escorzada, con la pierna derecha adelantada y flexionada, muy similar a la de las figuras de san Pedro y san Pablo de la puerta de la Barbazana.

El esquema dispositivo del manto de san Bartolomé (Fig. 5) es asimismo muy parecido al de la misma prenda del apóstol de los gentiles de la Barbazana y además en ambas esculturas está dotado de un fiador idéntico constituido por

39. MARTíNEZ ÁLAVA, C., "La catedral...", pp. 318-319.

40. Una descripción y comparación detallada de las claves y el tímpano en FERNÁNDEZLADREDA, C., "El maestro...", pp. 312-315.

41. Una descripción y comparación detallada de estas estatuas y el tímpano del Amparo en FERNÁNDEZ-LADREDA, C., "El maestro...", pp. 314-315. 
un cordón doble rematado en borlas, coincidencia particularmente significativa por tratarse de un detalle secundario. Tanto en la imagen de Santiago como en la de san Bartolomé, el tratamiento del plegado, con su tendencia a la angulosidad y el acartonamiento, concuerda con lo visto en los apóstoles del primer plano del tímpano del Amparo y en las figuras de la puerta de la Barbazana. Además los libros que portan con sus cuatro aplicaciones en forma de margarita en los ángulos y su broche con remate romboidal son idénticos a los que llevan los apóstoles de la portada de la capilla Barbazana.

Los cabellos y barbas de las esculturas puentesinas, con sus largos mechones sembrados de ondas muy marcadas a modo de meandros, recuerdan los de san Pablo enjugándose las lágrimas y el apóstol situado sobre san Juan tangente a la arquivolta del tímpano del Amparo o la clave del río Fisón. En los rostros cabe destacar el detalle de la boca entreabierta, dejando ver los dientes, rasgo muy poco habitual, pese a lo cual lo encontramos también en algunos apóstoles del tímpano del Amparo, como el san Pedro oficiante o el san Pablo lloroso.

Por su parte, las cabezas de la Dolorosa y san Juan de Viana (Fig. 6) presentan una torsión de cuello que recuerda a la de algunos apóstoles del tímpano del Amparo, en especial el san Pedro oficiante y el san Juan. Además la de María parece casi un trasunto de la de la Virgen

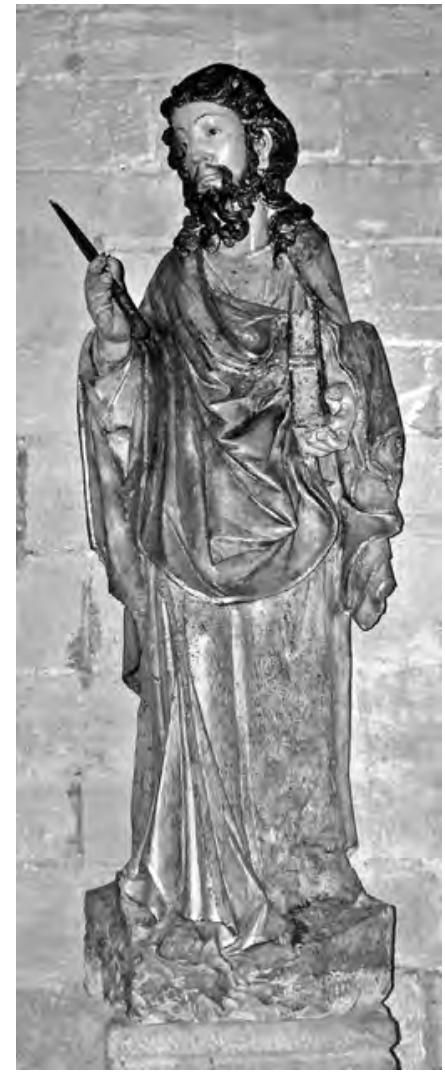

Figura 5. Estatua de san Bartolomé. Iglesia de Santiago de Puente la Reina (foto Archivo Servicio Patrimonio HistóricoInstitución Príncipe de Viana, Gobierno de Navarra). muerta del tímpano de la portada claustral. En el caso de san Juan su rostro resulta similar al del rio Fisón, en tanto el tratamiento de la cabellera se acerca al de las imágenes puentesinas.

\section{Cronología}

A partir de la vinculación de las realizaciones catedralicias del maestro del tímpano del Amparo con las fases constructivas claustrales ${ }^{42}$ podemos plantear

42. FERNÁNDEZ-LADREDA, C., "El claustro y dependencias canonicales de la catedral de Pamplona", FERNÁNDEZ-LADREDA, C. (directora), El arte gótico en Navarra, en prensa. 


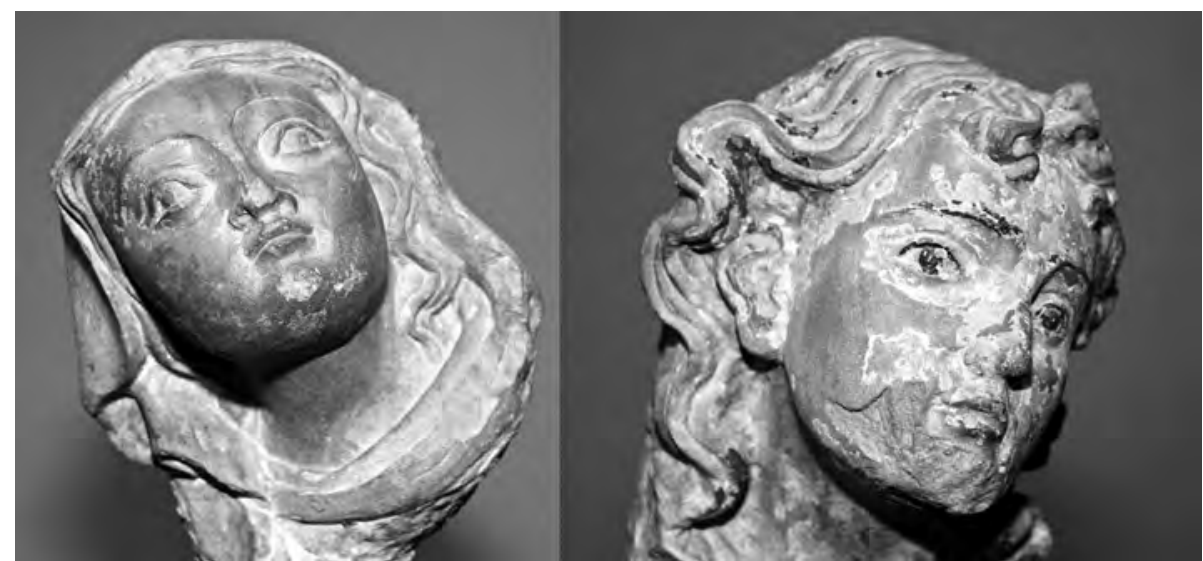

Figura 6. Cabezas de la Dolorosa y san Juan Evangelista, procedentes de Viana, hoy en el Museo de Navarra.

una hipotética cronología de las mismas. El límite postquem vendría dado por la clave del viento Subsolano, que corresponde a la primera fase (c. 12801320) y más concretamente a su segunda mitad, que podríamos situar entre 1300 y 1320, aproximadamente. El ante quem por la puerta del Amparo, perteneciente a la segunda fase (1320-1325) y, por su localización, a los momentos iniciales de la misma, h. 1320.

Tendríamos así una horquilla entre 1300 y 1320 . Incluso, si admitimos la inspiración del tímpano del Amparo en la tabla de Giotto de la Gemäldegalerie de Berlin, dada su datación (h. 1310), podríamos retrasar el límite post quem y concretar un poco más, situando la actuación del maestro del tímpano del Amparo en el claustro catedralicio entre 1310 y 1320 más o menos.

Aunque sin una certeza total, nos inclinamos a pensar que nuestro artífice pudo llegar de la mano del obispo Arnalt de Puyana (1310-1316), pero habría continuado su actividad durante los primeros años del episcopado de Arnaldo de Barbazan (1318-1355), al que atribuimos la paternidad del programa del tímpano.

Más difícil, dada su descontextualización, resulta proponer una cronología para las esculturas de Puente la Reina y Viana, pues tanto pueden ser coetáneas como posteriores a las obras catedralicias ${ }^{43}$.

43. Por lógica descartamos que sean anteriores, pues lo normal es que un maestro de este nivel fuera llamado para trabajar en una empresa de primer rango, como el claustro catedralicio, y, a partir de ahí, recibiera encargos para otros lugares. 


\section{Filiación}

La cuestión de la procedencia y formación del maestro del tímpano del Amparo es un problema arduo, al que por el momento no podemos dar una respuesta segura, todo lo más plantear alguna hipótesis plausible.

En tiempos se propuso un origen alemán ${ }^{44}$. Posteriormente, se planteó su derivación del famoso taller languedociano de Rieux ${ }^{45}$.

Actualmente, tras un cuidadoso cotejo entre las esculturas atribuidas al maestro del tímpano del Amparo -especialmente esta obra- y las estatuas de la capilla de Rieux, opino que el maestro en cuestión no puede identificarse con ninguno de los artistas que participaron en la decoración de la capilla de Rieux, ni siquiera con el autor de las tallas de san Juan Bautista y san Antonio de Padua -que son las más próximas a las realizaciones navarras- ${ }^{46}$, pues las diferencias entre unas y otras resultan excesivas ${ }^{47}$.

Efectivamente las estatuas de Rieux se caracterizan -entre otros rasgos- por el empleo de nimbos con decoración radial y orla perlada en el borde, cuerpos verticalistas en actitud rígida, cabezas relativamente pequeñas y plegado a base de pliegues tubulares verticales o de cascadas de pliegues en cucurucho que

44. MAHN, H., Kathedralplastik in Spanien. Die monumentale Figuralskulptur in Alt-Kastilien, Leon und Navarra zwischen 1230 und 1380. Reutlingen, 1931, p. 53, al que siguen DURAN SANPERE, A. y AINAUD DE LASARTE, J., Escultura gótica. Madrid, 1956, p. 147. Últimamente, HIDALGO SÁNCHEZ, S., Recherches..., p. 56, a partir de las coincidencias entre la escultura del tímpano del Amparo y la estatuas del anciano Simeón del portal de San Francisco de la catedral de León, cuyo autor se supone de origen y formación alemana, aunque conocedor de la escultura remense, ha vuelto a plantear de nuevo la hipótesis de la procedencia alemana del maestro del tímpano del Amparo.

45. ESPAÑOL BELTRÁN, F., El arte gótico I. Madrid, 1989, pp. 81-82 y YARZA LUACES, J., El arte gótico II. Madrid, 1989, p. 64. La propuesta fue aceptada y desarrollada por otros historiadores, aunque con matices: MARTíNEZ ÁLAVA, C., "La catedral...", pp. 316-317, FERNÁNDEZ-LADREDA, C., "Análisis...", p. 16 e HIDALGO SÁNCHEZ, S., Recherches..., p. 56, quien posteriormente abandonó la hipótesis -HIDALGO SÁNCHEZ, S., La escultura del claustro gótico de la catedral de Pamplona (1280-1350). Tesis doctoral (inédita), Universidad de NavarraUniversité Charles de Gaulle de Lille, 2010, 174-179-.

46. La misma opinión sostiene la máxima especialista en el taller de Rieux, aunque se expresa con prudencia -PRADALIER-SCHLUMBERGER, M., "Le maître de Rieux et son influence en Navarre". Cuadernos de la Cátedra de Patrimonio y Arte Navarro, $n^{\circ} 3$, Presencia e influencias exteriores en el arte navarro, Actas del Congreso Nacional. Pamplona, 5-7 de noviembre de 2008. Pamplona, 2008, pp. 179-181-, si bien ella mantiene que el escultor del tímpano del Amparo conoció la obra del maestro de Rieux posición que, dada la cronología respectiva -1330-1350 para el maestro de Rieux y entre 1310 y 1320 para el del tímpano del Amparo-, no puedo compartir.

47. Algunas de las diferencias y coincidencias señaladas a continuación fueron ya advertidas por HIDALGO SÁNCHEZ, S., Recherches..., pp. 54-55. También coinciden casi en su totalidad con las apreciadas por PRADALIER-SCHLUMBERGER, M., "Le maître...", pp. 179-180. 
caen a partir de las manos. Por el contrario, en las esculturas navarras el nimbo -cuando aparece- es liso -acólitos- o cuadrilobulado -Cristo-, los cuerpos adoptan posturas dobladas o encorvadas -apóstoles del tímpano- o bien flexionan una pierna de forma bastante acusada -san Pedro y san Pablo de la sala capitular, san Bartolomé de Puente-, las cabezas resultan más bien grandes y los pliegues son preferentemente angulosos y muy marcados además -fórmula totalmente ausente en las realizaciones del taller de Rieux-.

El tratamiento de los rasgos faciales, cabellos y barbas resulta ciertamente similar, pero si se examinan detalladamente se aprecian diferencias de matiz. Así los ojos son alargados y hundidos en ambos casos, en las dos estatuas de Rieux y en las esculturas navarras, sin embargo en aquellas presentan unas patas de gallo que no encontramos en éstas y en cambio en las obras navarras los párpados destacan más al ser más gruesos y el inferior tiene el borde curvo. Los pómulos resultan igualmente acusados en los dos casos, aunque en las realizaciones francesas las mejillas están hundidas y en las navarras son más carnosas. Las cabelleras y barbas están constituidas a base de formas onduladas en unas y otras, pero en las estatuas de Rieux encontramos un tipo de mechones enrollados sobre sí mismos a modo de virutas y rematados en una especie de botón -barba de san Juan Bautista-, que acabaran por convertirse en uno de los rasgos característicos de este taller, que faltan totalmente en las esculturas navarras, donde los mechones simplemente se ondulan y enlazan unos con otros como los meandros de un río.

Sin embargo, no es menos cierto que existen notas comunes. Algunas son más genéricas: búsqueda del realismo en los rostros y tendencia al preciosismo en el tratamiento de barbas y cabelleras. Otras mucho más específicas y por ello más significativas: hombros estrechos, manos estilizadas y bien modeladas con dedos finos y uñas marcadas, $y$, sobre todo, determinados rasgos faciales, como las arrugas surcando la frente, el entrecejo fruncido y la boca entreabierta dejando ver los dientes.

No parece que estos paralelismos puedan explicarse por una mera coincidencia, sino que habría que pensar en algún tipo de relación entre las estatuas de Rieux y las esculturas pamplonesas. Descartada la identidad de autores, habría que plantear la existencia de una vinculación indirecta: quizás haya que pensar en una fuente común, acaso alguna obra del sur de Francia -del Languedoc o de fuera de él-, desaparecida, anterior tanto a las esculturas pamplonesas como a las obras del taller de Rieux, donde coincidieron el maestro del tímpano del Amparo y alguno de los artistas que posteriormente integraron el taller de Rieux ${ }^{48}$. La participación en las obras del claustro catedralicio pamplo-

48. En esta línea se ha planteado la hipótesis de una común formación tolosana de sus artífices, quizás en la cantería de la catedral de Toulouse -MARTíNEZ ÁLAVA, C., "La catedral...", 
nés de un artista procedente de la Francia meridional resulta verosímil dadas las relaciones existentes por estos años entre el clero catedralicio pamplonés -obispos y cabildo- y el sur de Francia, particularmente -aunque no en exclusivaToulouse y Aviñón ${ }^{49}$. De otro lado la hipotética procedencia de nuestro artista de esa zona, se vería reforzada por su presunto conocimiento de la obra giottesca, que pudo llegar vía Aviñón, quizás a través de sus propias obras que fueron Ilevadas a la ciudad del Ródano ${ }^{50} \mathrm{o}$ por intermedio de su más próximo seguidor, el maestro de San Giorgio, cuya presencia allí está acreditada desde la década de 1320 y puede que antes ${ }^{51}$.

p. 317-, pero ha sido rechazada, alegando que esa escultura tolosana precedente no presenta las características específicas del maestro del tímpano del Amparo sino, precisamente, los rasgos del taller de Rieux que están ausentes en aquel -HIDALGO SÁNCHEZ, S., Recherches..., p. 55-. Asimismo se ha propuesto la posibilidad de una común formación bordelesa, concretamente en la cantería de la catedral de Burdeos, pues parece muy probable que el maestro de Rieux fuera de origen y formación bordelesa -MUNDT, B., "Der statuenzyklus der chapelle de Rieux und seine kunstlerische nachfolge". Jahrbuch der Berliner Museum, 1967, p. 42 y PRADALIER-SCHLUMBERGER, M., Toulouse et le Languedoc: la sculpture gothique, XIII-XIVè siècles. Toulouse, 1998, pp. 230 y 233, quien incluso lo identifica con un escultor citado en la documentación tolosana, Petrus de Sancto Melio, es decir de Saint-Émilion, precisamente una localidad del Bordelais-, pero se ha visto que tal propuesta plantea los mismos problemas que la hipótesis anterior -HIDALGO SÁNCHEZ, S., Recherches..., pp. 55-56-.

49. Una exposición detallada de estas relaciones -basada en datos obtenidos de GOÑI GAZTAMBIDE, J. Historia...-, en FERNÁNDEZ-LADREDA, C. y LORDA, J., "La catedral gótica. Arquitectura", La catedral de Pamplona. Pamplona, 1994, t. I, p. 235.

50. CASTELNUOVO, E., Un pittore italiano alla corte di Avignone: Matteo Giovanetti e la pittura in Provenza nel secolo XIV. Turín, 1962, p. 26, nota 2.

51. MANZARI, F., "La miniatura nel secolo di Giotto", TOMEl, A. (dir.), Giotto e il Trecento. Il piu Sovrano Maestro stato in dipintura. Milán, 2009, p. 279. 